\title{
A new genus and species of Heligmonellidae (Nematoda: Trichostrongylina) parasitic in Delomys dorsalis (Rodentia: Sigmodontinae) from Misiones, Argentina
}

\author{
María Celina Digiani ${ }^{1,2}$ and John M. Kinsella ${ }^{3}$ \\ ${ }^{1}$ CONICET- Consejo Nacional de Investigaciones Científicas y Técnicas, Argentina; \\ ${ }^{2}$ División Zoología Invertebrados, Facultad de Ciencias Naturales y Museo, Universidad Nacional de La Plata, Argentina; \\ ${ }^{3}$ HelmWest Laboratory, Missoula, Montana, USA
}

\begin{abstract}
Alippistrongylus bicaudatus gen. et sp. n. (Nematoda: Heligmonellidae) is described from the striped Atlantic forest rat, Delomys dorsalis (Hensel) (Rodentia: Sigmodontinae), from the province of Misiones in Argentina. The new genus and species is characterised by a synlophe of 21 unequal ridges in both sexes without a gradient in size, with two ridges weakly sclerotised and oriented perpendicularly in the dorsal left quadrant; males with a highly dissymmetrical bursa with a hypertrophied right lobe, and females with a dorsal conical appendage just posterior to the vulva, conferring a two-tailed appearance to the female worms.
\end{abstract}

Keywords: taxonomy, Nippostrongylinae, synlophe, right lobe hypertrophy, right lobe rotation, caudal appendage, South America

The genus Delomys Thomas (Rodentia: Sigmodontinae) is composed of three species distributed in the South American Atlantic Forest, mainly in southeastern Brazil. One of these species, the striped Atlantic forest rat, Delomys dorsalis (Hensel), is also found in the province of Misiones, Argentina. The affinities of Delomys with the other sigmodontines are still uncertain and the genus is currently considered as incertae sedis (Wilson and Reeder 2005). Records of macroparasites for species of Delomys are very scarce and include only fleas (Siphonaptera): Polygenis (Polygenis) rimatus (Jordan, 1932) (Rhopalopsyllidae) and Tunga caecata (Enderlein, 1901) (Tungidae), reported from $D$. dorsalis in different localities of Brazil (Moraes et al. 2003, Lareschi and Linardi 2005). No helminth parasites have been reported from $D$. dorsalis or from other species of Delomys. The aim of this work is to report the first helminth parasites known for this host. The specimens studied were found to belong to a new genus and species of Heligmonellidae (Nematoda: Heligmosomoidea), and are described herein.

\section{MATERIALS AND METHODS}

Rodents $(n=4)$ were captured in the Reserva de Vida Silvestre Urugua-í (belonging to the Fundación Vida Silvestre Argentina), Misiones Province, Argentina. The nematodes recovered were fixed and stored in $70 \%$ ethanol. The synlophe was studied following Durette-Desset (1985) and the nomenclature referring to the axis of orientation follows Durette-Desset and Digiani
(2005). The ridges are considered as dorsal or ventral with respect to the axis of orientation and not in relation to the lateral hypodermal cords. Ridges are numbered from left to right, from 1 to $n$ for dorsal ridges and from 1' to $n$ ' for ventral ridges. The nomenclature used for the study of the caudal bursa follows Durette-Desset and Digiani (2012). The nomenclature for parasites above the family group follows Durette-Desset and Chabaud (1993). Measurements are given in micrometres, unless otherwise stated, as the range of paratypes followed, in parentheses, by the mean of paratypes and measurement of holotype/allotype. $\mathrm{SpL} / \mathrm{BL}$ and $\mathrm{UtL} / \mathrm{BL}$ mean the proportion (in percentage) of the spicule length to the body length and of the uterus length to the body length, respectively. Type and voucher specimens of parasites are deposited in the Helminthological Collections of the Museo de La Plata, La Plata, Argentina (MLP-He), the Institute of Parasitology, České Budějovice, Czech Republic (IPCAS), and the Muséum national d'Histoire naturelle, Paris, France (MNHN). The nomenclature of the hosts at species level follows Wilson and Reeder (2005). Voucher specimens of hosts are deposited in the Mammals National Collection of the Museo Argentino de Ciencias Naturales 'Bernardino Rivadavia', Buenos Aires, Argentina (MACN-Ma).

\section{RESULTS}

Suborder Trichostrongylina Durette-Desset et Chabaud, 1993

Superfamily Heligmosomoidea Durette-Desset et Chabaud, 1993

Family Heligmonellidae Skrjabin et Schikhobalova, 1952 
Subfamily Nippostrongylinae Durette-Desset, 1971

Alippistrongylus gen. n.

Diagnosis. Synlophe with uninterrupted ridges, unequal in size but not markedly so. Ridges on left dorsal quadrant with reduced struts and oriented perpendicularly to body surface. Axis of orientation of ridges directed from ventral right to dorsal left quadrant, with inclination of about $60^{\circ}$ to sagittal axis at mid-body. Bursa highly dissymmetrical, with hypertrophied right lobe. Bursal pattern of type 1-4 or 4-1. Genital cone well-developed. Females with dorsal conical appendage just posterior to vulva. Parasites of Neotropical Sigmodontinae (Rodentia, Cricetidae).

Type and only species: Alippistrongylus bicaudatus gen. et sp. $n$.

Ety mology: The genus is named in honour to the memory of Angel R. 'Alippi' Digiani, beloved father of the first author.

Differential diagnosis. The presence of a cephalic vesicle and of a synlophe which is not bilaterally symmetrical allows us to place these specimens in the superfamily Heligmosomoidea; and specifically in the family Heligmonellidae, as redefined by Durette-Desset (1983) and Durette-Desset and Chabaud (1993), by the presence of an oblique axis of orientation of the synlophe, a bursal pattern different from types 2-1-2 and 3-2, and the female monodelphic and lacking a caudal spine.

Moreover, several characters of the synlophe, i.e. ridges continuous and all around the body, the number of ridges (more than 13), with ventral ridges more numerous than the dorsal ridges, together with the extreme dissymmetry of the caudal bursa (right and left lobes of differing size and different arrangement of rays on each side), allow us to place this genus within the subfamily Nippostrongylinae (Durette-Desset 1985).

In some characters of the synlophe such as the number and size of the ridges, these specimens are close to species of the genera Hassalstrongylus Durette-Desset, 1971 and Stilestrongylus Freitas, Lent et Almeida, 1937. Hassalstrongylus comprises 16 species with 19-25 ridges (more commonly 22-24), unequal but always of comparable size, whereas Stilestrongylus comprises 24 species with 24-30 ridges (more commonly 25-27), subequal in size, usually with 1 or 2 slightly larger ridges. A gradient in ridge size is also absent in species of both genera. However, the presence of 2 ridges with reduced struts and oriented perpendicularly to the body surface has not been observed in any species of Hassalstrongylus or Stilestrongylus which, independently of the number and size of the ridges, show uniform ridges with well developed cuticular struts.

The dissymmetry of the caudal bursa and the presence of a well developed genital cone also relate these specimens to species of Stilestronglus but as well to species of the genera Malvinema Digiani, Sutton et Durette-Desset,
2003 and Suttonema Digiani et Durette-Desset, 2003. However, the four known species of Malvinema are characterised by a synlophe with a quadruple gradient in ridge size, whereas the only described species in Suttonema has 11-12 ridges, strongly unequal in size, and ridges rounded without cuticular support on the entire dorsal surface (Digiani and Durette-Desset 2003, Digiani et al. 2003).

On the other hand, the extreme dissymmetry of the bursa is also remarkable. In species of Stilestrongylus, Malvinema and Suttonema, the right lobe is always larger and it may show different degrees of development. However, the extraordinary lateral development and, especially, the particular rotation of the right lobe displayed by these specimens have never been observed among species of these genera. Finally, the dorsal appendage of the females, consisting of a dorsal conical projection, which does not involve internal organs such as the ovejector or the intestine, also seems to be unique among the Trichostrongylina. The combination of these characters allows us to propose the erection of a new genus and species for these specimens, to which we propose to give the name of Alippistrongylus bicaudatus gen. et sp. $\mathrm{n}$.

Alippistrongylus bicaudatus gen. et sp. n. Figs. 1-20

General description: Small nematodes, loosely and irregularly coiled, or uncoiled. Excretory pore and deirids at same level, at about $77 \%$ of oesophagus length in males, within $63-78 \%$ in females. Nerve ring just anterior to excretory pore and deirids (Fig. 1).

Head: Cephalic vesicle present. Two amphids, 4 externolabial papillae and 4 submedian cephalic papillae visible in lateral view. Labial and cephalic papillae connected under the cuticle by semi-circular structures (Fig. 2). In apical view, rounded buccal opening surrounded by very thin ring, papillae hardly visible (Fig. 3).

Synlophe (studied in 1 male, 2 complete females and 1 female posterior fragment, all paratypes): In both sexes cuticle bearing longitudinal, uninterrupted ridges appearing gradually posterior to cephalic vesicle, disappearing just anterior to bursa in male and reaching caudal appendage in female. Number of ridges between cephalic vesicle and nerve ring: 14 (female) (Fig. 4); at level of distal oesophagus: 17 (male); just post-oesophageal: 19 (female) (Fig. 5). Number of ridges at mid-body: 21 in both sexes, 9 dorsal/12 ventral (Figs. 6, 7). Within posterior third of body length: 20-21 in female (Fig. 8), 21 in male. At mid-body, ridges unequal in size, with smaller ridges on dorsal left and ventral right quadrant. Gradient in ridge size absent. Most ridges with well developed cuticular struts, except 2 left ridges determining the axis of orientation (ridges 1 and 1'), smaller and with weak cuticular support, oriented perpendicularly to body surface (Figs. 6, 7). Largest ridges: ridge 2' and right dorsal ridge just above right lateral cord (ridge 7 ). Single axis of orientation of ridges inclined at about $60^{\circ}$ to sagittal axis 

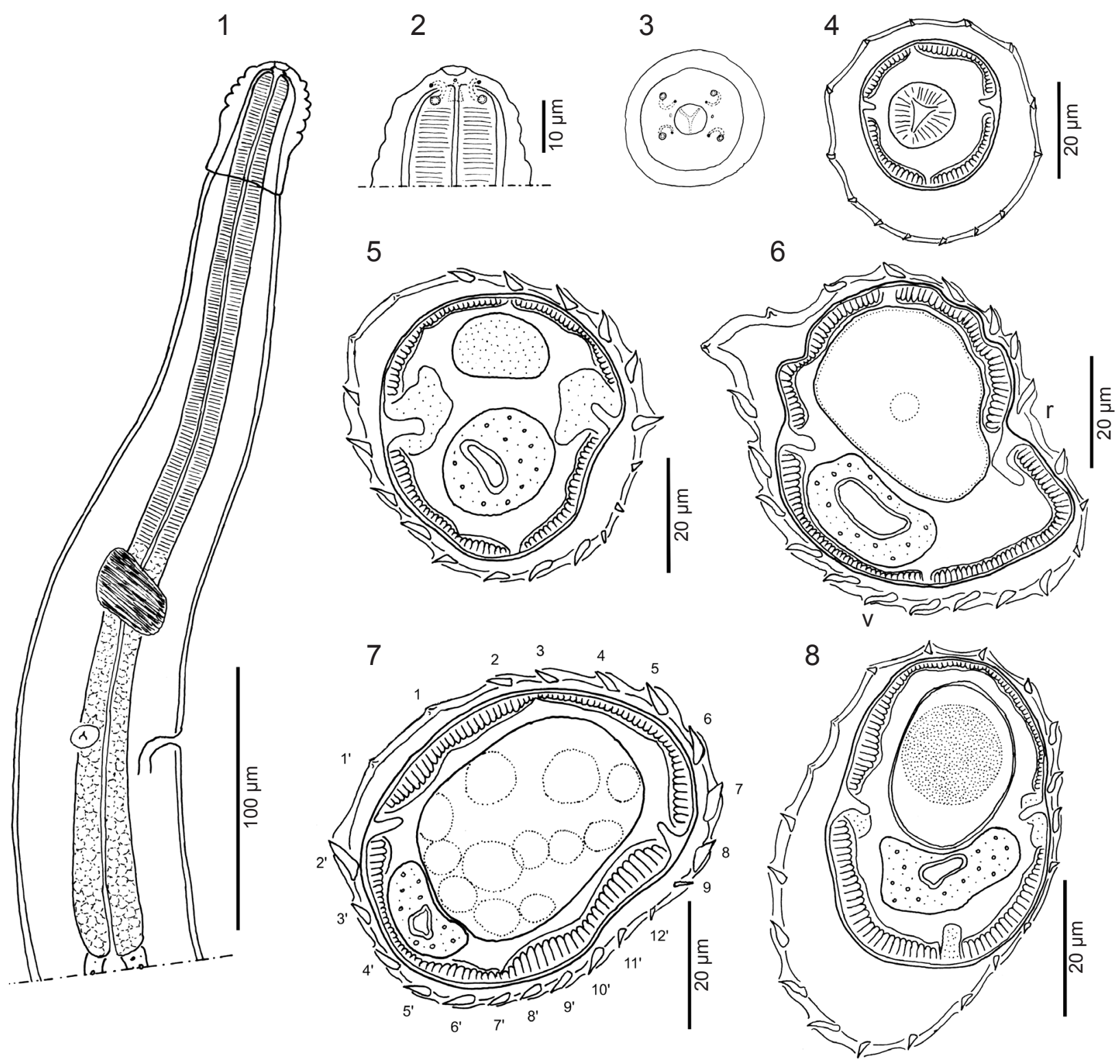

Figs. 1-8. Alippistrongylus bicaudatus gen. n. et sp. n. from Delomys dorsalis. Fig. 1. Female, anterior extremity, right lateral view. Fig. 2. Female, head, lateral view. Fig. 3. Head, apical view, schematic, not in scale. Figs. 4-8. Synlophe in transverse sections of the body: between cephalic vesicle and nerve ring (female) (4); just post-oesophageal (female) (5); at mid-body of female (6) and male (7); within distal third of body length (female) (8). Abbreviations: $\mathrm{r}$ - right, $\mathrm{v}$ - ventral. All sections oriented as in Fig. 6.

in both sexes. Within distal third of body length: size and orientation of ridges similar to those at mid-body (Fig. 8).

Male (holotype and 3 paratypes): 2.75-3.70 (2.96, $2.75) \mathrm{mm}$ long and $70(70,80)$ wide at mid-body. Cephalic vesicle $40-45(42,40)$ long and $30(30,30)$ wide. Nerve ring, excretory pore and deirids situated at 165-180 (172, 160), $245(\mathrm{n}=1)(220)$ and 220-270 $(248,220)$ from apex, respectively. Oesophagus $305-320(312,310)$ long.

Bursa strongly dissymmetrical (with dorsal ray passing through sagittal axis of worm and one lateral lobe larger than the other; see Durette-Desset and Digiani 2012). Right lobe hypertrophied (Figs. 9-13). Bursa extremely difficult to spread out due to extreme lateral development and rotation of right lobe.

Right lobe folded on dorsal lobe and twisted on its major axis, resulting in distal extremities of right rays 2-5 directed to the left, and in right ray 2 appearing as 'posterior' to trunk formed by rays 3-5 (Fig. 10); left lobe directed frontally and folded ventrally in its distal part (Fig. 9).

Right lobe with pattern of type 4-1, with right ray 6 arising first from common trunk of rays 2-6 (Fig. 9). Rays 2 to 5 much longer than rays 6 (Figs. 9, 10, 13). Ray 2 well separated from common trunk formed by rays 3-5 and supporting ventral margin of lobe (Fig. 13). Rays 3-5 


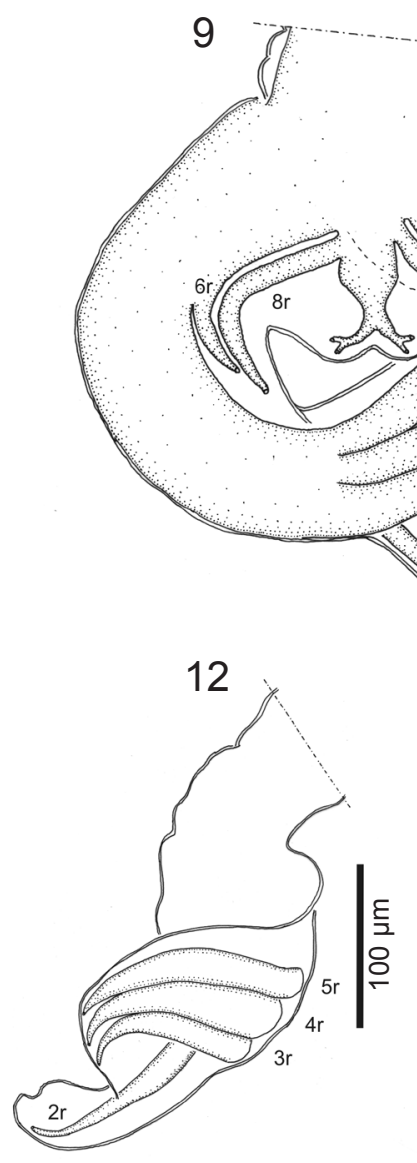

16

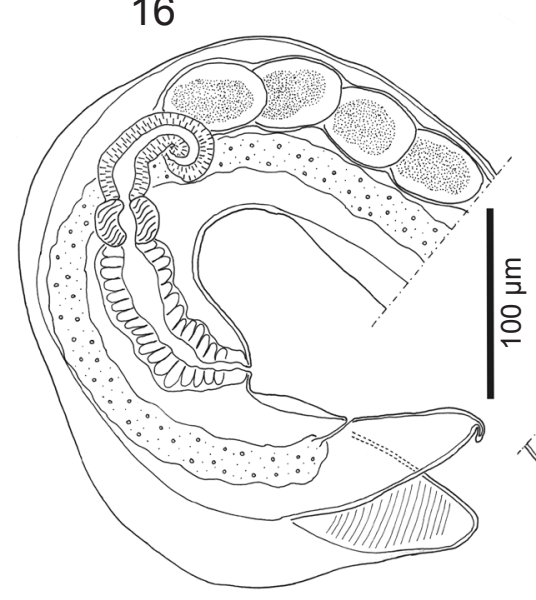

13

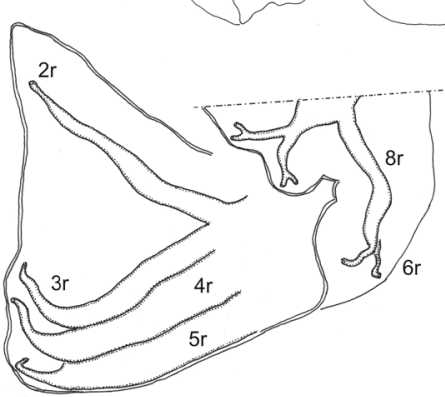

17

11
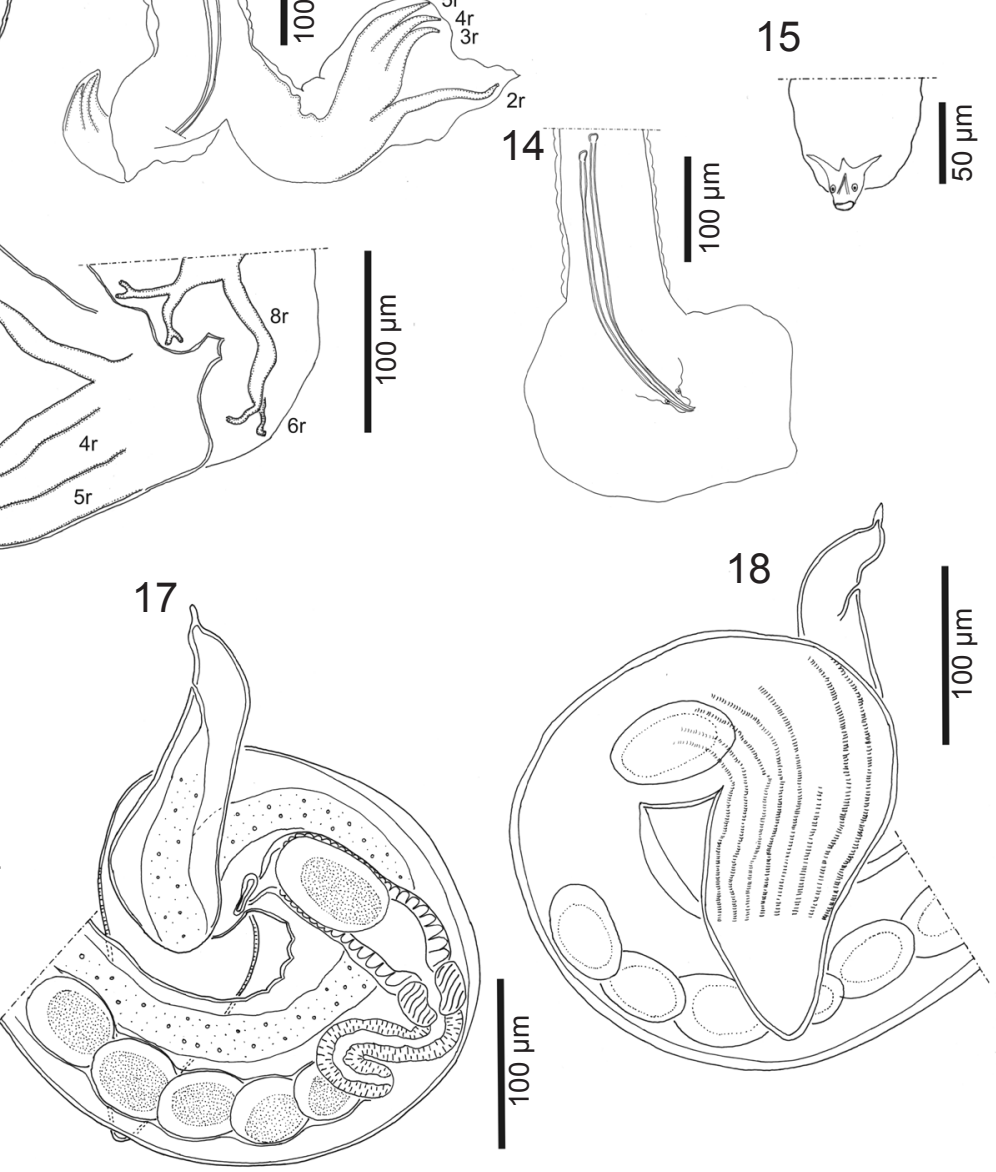

Figs. 9-18. Alippistrongylus bicaudatus gen. n. et sp. n. from Delomys dorsalis. Figs. 9-13. Male, bursa. Figs. 9, 10. Bursa with right lobe split between rays 4 and 5. Fig. 9. Ventral view, right lobe displaced posteriorly, genital cone omitted. Fig. 10. Dorsal view, left lobe omitted. Fig. 11. Silhouette of entire bursa in dorsal view, right lobe unfolded and rolled on its long axis. Fig. 12. Right lobe, rays 3-5 partly rolled on ray 2. Fig. 13. Right lobe, unrolled. Fig. 14. Male, silhouette of posterior extremity in lateral view. Fig. 15. Genital cone, ventral view. Figs. 16-18. Female, posterior extremity. Fig. 16. Right lateral view, showing distal uterus, ovejector, tail and dorsal appendage. Fig. 17. Divergence of dorsal appendage and ventral portion including tail, ventral view. Fig. 18. Same as Fig. 17. in dorsal view, internal structures (except eggs) omitted. Abbreviations: $21-81$ - left rays $2-8 ; 2 \mathrm{r}-8 \mathrm{r}$ - right rays $2-8$.

diverging at distal extremity, supporting lobe laterally (Figs. 11-13). Ray 6 short (Figs. 9, 10).

Left lobe with pattern of type 1-4, with left ray 2 arising first from common trunk of rays 2-6 (Fig. 9). Rays 3-5 long, divergence not observed, probably at extremi- ties. Rays 6 short, origin from common trunk distal to that of rays 2 (Fig. 9).

Dorsal lobe short. Rays 8 elongated transversally, arising asymmetrically from dorsal ray, with extremities close to rays 6 . Left ray 8 longer than right one. Dorsal 

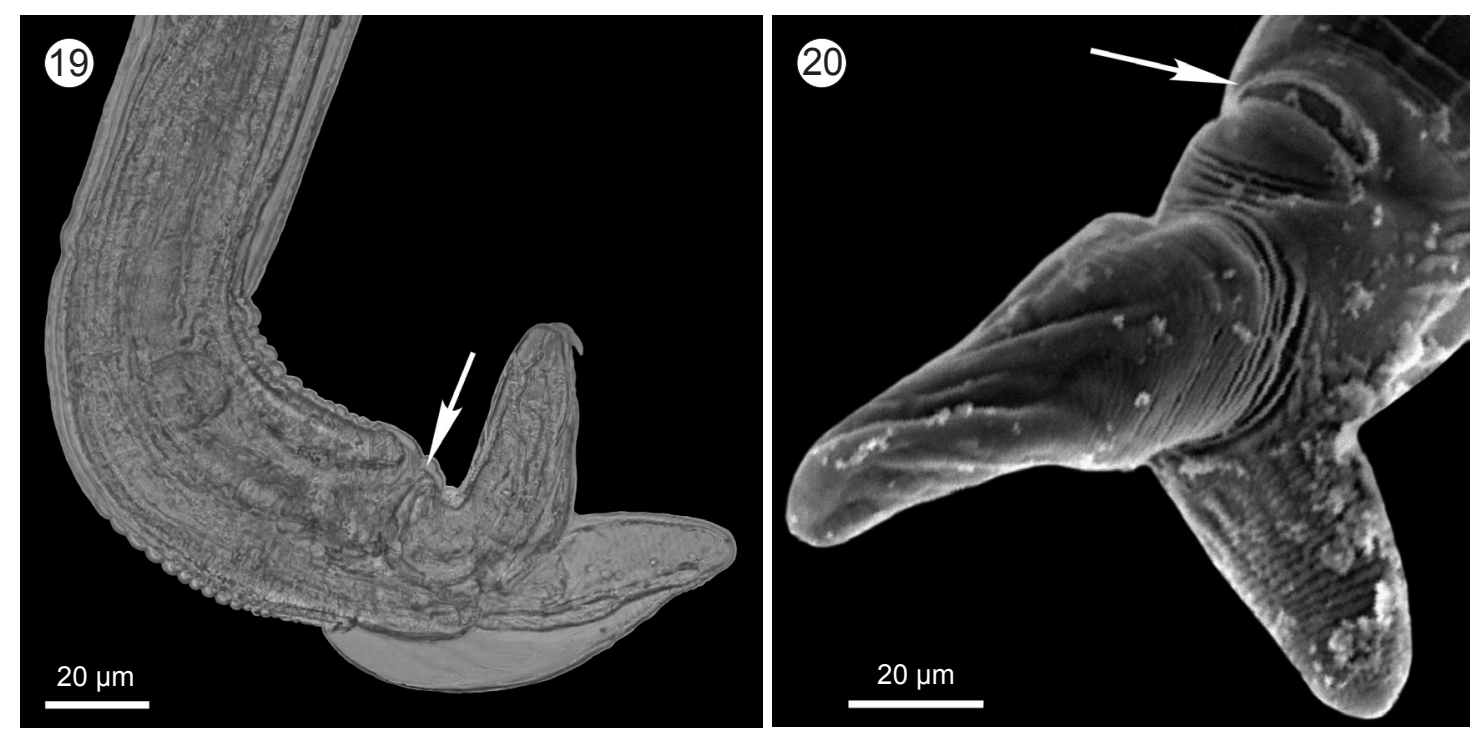

Figs. 19-20. Alippistrongylus bicaudatus gen. et sp. n. from Delomys dorsalis. Female caudal end. Fig. 19. Lateral view, light microscope. Fig. 20. Ventral view, SEM. Arrows indicate vulval aperture.

ray short, thick at base, thinner at mid-length and divided at its distal third into two branches, each one divided into two sub-branches, rays 9 (external) and rays 10 (internal) (Fig. 9). Genital cone stout, well developed, with internal sclerotisation, $60(n=2)(40)$ long and 45, $50(n=2)(40)$ wide at base; papillae 7 large and sessile, papilla 0 not observed (Fig. 15). Spicules subequal, alate, $295(\mathrm{n}=2)$ (290) long, distally bent, ending in sharp tip (Fig. 14). SpL/BL 9.6, 10.7\% (10.5\%). Gubernaculum not observed.

Female (allotype and 12 paratypes, 10 complete +2 fragments): $2.95-3.75(3.40,3.22) \mathrm{mm}$ long and 60-90 $(75,70)$ wide at mid-body. Cephalic vesicle 40-50 (42, 40) long and 30-40 $(33,30)$ wide. Nerve ring, excretory pore and deirids situated at 120-190 $(154,170), 210-240$ $(\mathrm{n}=7)(224,230)$ and $210-240(\mathrm{n}=8)(227,230)$ from apex, respectively. Oesophagus 260-340 (n = 11) (309, 295) long.

Monodelphic. Vulva situated at 120-210 (164, 190) from caudal extremity. Vagina vera $10-15(\mathrm{n}=4)(12,20)$ long, vestibule 50-110 ( $\mathrm{n}=9)(88,70)$, sphincter $22-35$ $(27,30)$ long and $30-40(n=9)(34,38)$ wide, infundibulum 90-110 ( $\mathrm{n}=3)$ (97, 70 minimum) long (Fig. 16). Uterus 500-850 long $(\mathrm{n}=8)(695,640)$ long, containing $12-23,(16,12)$ eggs, 40-66 (45-50) long and 30-45 (30-33) wide $(\mathrm{n}=30)$. UtL/BL 14.1-24.3\% (19.8\%, $19.9 \%)$.

Posterior extremity dividing just behind vulva into a dorsal conical appendage and ventral postvulval portion including tail (Figs. 16-20). Ventral portion (mucron included) $113-185(\mathrm{n}=10)(143,155)$ long. Tail (mucron included) 50-75 $(\mathrm{n}=6)(59,50)$ long. Distal mucron $12-25(\mathrm{n}=10)(16,15)$ long. Dorsal appendage 85-140 $(122,125)$ long and $35-80(\mathrm{n}=10)(56,55)$ wide at base, bearing cuticular inflation (Figs. 16, 19).
Type host: Delomys dorsalis (Hensel) (Rodentia: Cricetidae: Sigmodontinae). Deposited under MACN-Ma 22.254.

Type locality: Reserva de Vida Silvestre Urugua-í $\left(25^{\circ} 59^{\prime} \mathrm{S} ; 5^{\circ} 05^{\prime} \mathrm{W}\right)$, Departamento General Manuel Belgrano, Misiones Province, Argentina.

Site: Small intestine.

Prevalence and intensity of infection: 2 out of 4 hosts examined (50\%) parasitised with 18 and 1 worms, respectively.

Type material: Male holotype MLP-He 6722, female allotype MLP-He 6723. Paratypes: 1 male, 6 females MLP-He 6724; 1 female MNHN 70YT; 1 female IPCAS N-1057.

E t y m olog y: From Latin bi (two) and cauda (tail) referring to the forked posterior extremity, which confers to the females the appearance of a two-tailed worm.

\section{DISCUSSION}

In a survey of the nature and phylogenetic distribution of vulval appendages in nematodes, Carta et al. (2009) unified the nomenclature for the different structures observed: vulval membranes are paired lateral cuticular outgrowths, perpendicular to the vulval slit, whereas vulval flaps are mild-to-extreme modifications of the anterior vulval lip. Both structures have been described in the Trichostrongylina, especially in the Ostertagiinae Skrjabin et Schultz, 1937 and Haemonchinae Skrjabin et Schultz, 1937 (Trichostrongyloidea); in these latter an important amount of body wall may be involved in the flaps of some species (Gibbons 1979, Lichtenfels et al. 2001, Carta et al. 2009). Highly developed appendages, paired but with unequal development on both sides, referred to as 'projections', were also reported in Copemania darwini Beveridge et Durette-Desset, 2009 (Heligmosomoidea: Nicollinidae) parasitic in Australian marsupials (Dasyu- 
ridae and Peramelidae). These projections seem to correspond to the second category (vulval flaps).

The vulval flaps may be hypertrophied to the point that, when the vulva is located near the caudal end, the latter may show a forked appearance [see fig. 4 of $C$. darwini in Beveridge and Durette-Desset 2009, and especially fig. 42 of an unidentified trichostrongyloid from Tragelaphus scriptus (Pallas) (Artiodactyla) in Gibbons and Khalil 1980].

However, the character observed here is unlikely to be homologous of the vulval flaps. The particularity of these specimens is that the structure observed is not strictly related to the vulva, which has no particular modifications. It consists of a dorsal conical projection or appendage, which does not involve internal organs such as the ovejector or the intestine. This projection mimics in size and form the postvulval portion of the body, which includes the tail. It bears a cuticular inflation and the cuticular ridges running along the whole body length continue on the appendage rather than on the ventral postvulval portion, which includes the true tail.

It is worth noting that the vulval flaps in Haemonchus Cobb, 1898 and several ostertagiines are variable in occurrence, not only within genera but also among conspecifics; they are considered unreliable even for species-level identification (Carta el al. 2009). On the contrary, the dorsal appendage in the new species described was observed in all the females examined and it seems unlikely to be a character with intraspecific variation. Due to its uniqueness, it was here considered a generic character, though its taxonomic value could eventually be re-assessed.

The function of this appendage is enigmatic. It is possible that the development of such structure parallels the extreme hypertrophy and rotation of the right bursal lobe in the male, the other striking character of the genus, so that both modifications may interact together in order to achieve a better attachment during copulation. At the moment this remains a hypothesis, which will probably be corroborated by the finding of new material, especially of paired males and females.

Acknowledgements. Thanks are due to Javier A. Pereira (Museo Argentino de Ciencias Naturales, Buenos Aires, Argentina) and Pablo Beldomenico (Instituto de Ciencias Veterinarias del Litoral, Santa Fe, Argentina) for collecting hosts and parasites, respectively, and to Fundación Vida Silvestre Argentina for facilitating the access to the Reserve. Patricia Sarmiento (Servicio de Microscopía Electrónica, Museo de La Plata, La Plata, Argentina) provided SEM photographs. Ian Beveridge (University of Melbourne, Australia) kindly helped with the bibliography. Thanks are also due to Julián F. Petrulevičius for valuable help and discussion and to the two anonymous reviewers whose suggestions helped improve the original manuscript. This work was partly supported by grants PIP 0006 from CONICET and PICT 2010-0924 from ANPCyT (Argentina).

\section{REFERENCES}

Beveridge I., Durette-Desset M.-C. 2009: A new species of the nematode genus Copemania (Nematoda: Trichostrongylida), parasitic in the western quoll, Dasyurus geoffroii and short-nosed bandicoot, Isoodon obesulus from south-western Western Australia. Rec. West. Austr. Mus. 25: 345-349.

Carta L.K., Handoo Z.A., Hoberg E.P., Erbe E.F., Wergin W.P. 2009: Evaluation of some vulval appendages in nematode taxonomy. Comp. Parasitol. 76: 191-209.

Digiani M.C., Durette-Desset M.-C. 2003: Suttonema delta n. g., n. sp. (Nematoda: Trichostrongylina: Heligmosomoidea) from an Argentinean sigmodontine rodent. Syst. Parasitol. 55: 33-38.

Digiani M.C., Sutton C.A., Durette-Desset M.-C. 2003: A new genus of Nippostrongylinae (Nematoda: Heligmonellidae) from the water rat Scapteromys aquaticus from Argentina. J. Parasitol. 89: 124-132.

Durette-Desset M.-C. 1983: Keys to genera of the superfamily Trichostrongyloidea. In: R.C. Anderson and A.G. Chabaud (Eds.), CIH Keys to the Nematode Parasites of Vertebrates. Commonwealth Agricultural Bureaux, Farnham Royal, Bucks, pp. $1-68$.

Durette-Desset M.-C. 1985: Trichostrongyloid nematodes and their vertebrate hosts: reconstruction of the phylogeny of a parasitic group. Adv. Parasitol. 24: 239-306.

Durette-Desset M.-C., Chabaud A.G. 1993: Note sur la nomenclature suprafamiliale des Strongylida. Ann. Parasitol. Hum. Comp. 68: 11-12.
Durette-Desset M.-C., Digiani M.C. 2005: The axis of orientation of the synlophe in the Heligmosomoidea (Nematoda, Trichostrongylina): a new approach. Parasite 12: 195-202.

Durette-Desset M.-C., Digiani M.C. 2012: The caudal bursa in the Heligmonellidae (Nematoda: Trichostrongylina). Characterisation and hypothesis on its evolution. Parasite 19: 3-18.

Gibbons L.M. 1979: Revision of the genus Haemonchus Cobbold, 1898 (Nematoda: Trichostrongylidae). Syst. Parasitol. 1: 3-24.

Gibbons L.M., Khalil L.F. 1980: Some new trichostrongylid nematodes from East African artiodactylids. Syst. Parasitol. 1: 91-104.

LARESChi M., Linardi P.M. 2005: New data on the morphology of Polygenis (Polygenis) rimatus (Jordan) (Siphonaptera: Rhopalopsyllidae). Neotrop. Entomol. 34: 121-125.

Lichtenfels J.R., Pilitt P.A., Gibbons L.M., Boomker J.D.F. 2001: Haemonchus horaki n. sp. (Nematoda: Trichostrongyloidea) from the grey rhebuck Pelea capreolus in South Africa. J. Parasitol. 87: 1095-1103.

Moraes L. B., Bossi D.E.P., Linhares A.X. 2003: Siphonaptera parasites of wild rodents and marsupials trapped in three mountain ranges of the Atlantic Forest in southeastern Brazil. Mem. Inst. Oswaldo Cruz 98: 1071-1076.

Wilson D.E., Reeder D.A.M. 2005: Mammal Species of the World. A Taxonomic and Geographic Reference, Third Edition. Johns Hopkins University Press, Baltimore, Maryland, $2142 \mathrm{pp}$. 